\title{
"La identidad imprevisible": La pérdida del reino y la correspondencia entre Elena Garro y José Bianco ${ }^{\mathrm{I}}$
}

Este artículo analiza la inclusión de fragmentos de cartas privadas de Elena Garro en el texto de La pérdida del reino de José Bianco. Este uso de contenido epistolar como material narrativo, descubierto mediante el cotejo de la novela con las cartas enviadas por Garro a Bianco hacia fines de la década de 1940, se inscribe dentro de la concepción que el escritor argentino tenía de la correspondencia como extensión natural de la obra literaria de un autor. En su novela, Bianco compone el personaje de Laura Estévez nutriéndose en gran parte de las palabras escritas por Garro, pero sometiéndolas a un minucioso proceso de edición que las resignifica como material narrativo. Así, esta apropiación de materiales documentales y aun íntimos en una obra de ficción se inscribe como un procedimiento compositivo que borronea programáticamente los límites entre "vida real" y creación literaria y por eso mismo ofrece, como un juego de espejos enfrentados, nuevos niveles de interpretación.

$$
\begin{aligned}
& \text { Idealizar [los recuerdos], concertarlos } \\
& \text { artísticamente, significa convertirlos en } \\
& \text { recuerdos ajenos, de alguna manera } \\
& \text { deshacerme de ellos, tirarlos por la borda, } \\
& \text { prescindir de la frágil tabla que todavía } \\
& \text { puede sostenerme. } \\
& \text { José Bianco, "Digresión" }
\end{aligned}
$$

Con una carta fechada en París el 29 de julio de 1947, Elena Garro inicia su comunicación epistolar con José Bianco, una relación escrita que se prolongará hasta $1974 .{ }^{2}$ Este arco temporal tiene también un despliegue, no menos extenso, en el espacio: muchas de esas cartas viajaron desde ciudades de Europa, de América y aun de Asia. Profusas en cantidad y ricas en contenido emocional, en ellas confluyen, inextricablemente, las efusiones de la amitié amoureuse, las fricciones de la ideología y los ritos de la complicidad literaria. Esa confluencia, infrecuente en los epistolarios de 
escritores latinoamericanos, les otorga una singularidad documental a partir de la cual puede explorarse el mundo literario y político que compartieron Garro y Bianco y los vínculos sutiles que los unieron. En tanto correspondencia entre un hombre y una mujer de letras, allí se comunican también, mezclados con los comentarios sobre sus vidas privadas más o menos compartidas, los esplendores y miserias de la creación literaria: ambos dan cuenta de los estados en los que se encuentran con respecto a sus propias obras, si están escribiendo, si han publicado o si planean hacerlo; se piden y se ofrecen colaboraciones y gestiones diversas.

Las cartas son la materia de la que está hecha, eminentemente, la amistad entre Bianco y Garro. En persona sólo tuvieron dos series de encuentros: la primera, más prolongada, corresponde a la estadía de ambos en París, cuando se conocen, a mediados de la década de I940. Entre 1946 y 1948, Bianco y el matrimonio Garro-Paz se ven con alguna frecuencia en la capital francesa y en otras partes de Europa. ${ }^{3}$ Veinte años más tarde, en 1967, Bianco viaja a México, con motivo del Segundo Congreso de la Comunidad Latinoamericana de Escritores, tras el cual se aloja en casa de Garro al menos una o dos semanas. Con excepción de estas dos ocasiones, la relación entre ellos fue casi exclusivamente epistolar - si bien hablaron por teléfono algunas veces, durante la década del 1970, a las que se alude en las cartas - (en este sentido, el vínculo entre ellos no es muy distinto del que unió a Garro con Adolfo Bioy Casares). ${ }^{4}$

En tanto intersección singular entre vida y escritura, las cartas - y en particular las cartas que escriben e intercambian autores de ficción - se transforman en un sedimento de la memoria que desafía la distinción proustiana entre recuerdos voluntarios e involuntarios. Para el Bianco ensayista, la preocupación por este encuentro de la vida con la letra escrita es central y sostenida. La relación enigmática que se tiende entre vida y obra, entre vida "real" y acción ficticia, entre autor y personaje, atraviesa casi todos los artículos y reseñas recogidos en Ficción y reflexión..$^{5}$ Estas exploraciones ensayísticas serán, inevitablemente, una suerte de guía de lectura que orientará en el futuro las lecturas críticas, no siempre unívocas, de su obra. ${ }^{6}$ En el que considero primer extremo de esta línea que atraviesa treinta años, "Digresión", de 1954, la reflexión intenta ser de orden impersonal, casi abstracto, como puede verse en el íncipit axiomático del ensayo: "Inconveniente de las novelas en primera persona del singular: los lectores asocian al autor con el personaje que relata los hechos" (150). Casi de inmediato, la reflexión pierde esta impersonalidad aparente o impostada para adentrarse en preocupaciones que son a la vez concretas e íntimas: la escritura en primera persona como recurso por 
excelencia del artificio narrativo. ${ }^{7}$ En el otro extremo, en "Parafernaria" [sic], de 1984 - es decir, separado del anterior por treinta años - Bianco estipula una taxonómica distinción entre la persona del escritor y su obra, valiéndose de comentarios de Marcel Proust y de Henry James. Esta clasificación abre en realidad el terreno de "los diarios literarios, las cartas, las memorias" que son "esa parafernaria literaria y artística que va unida a la obra de un artista creador" (27I). "Parafernaria" es una especie de manifiesto que se apoya en dos pilares esenciales: la idea de que las cartas - así como los diarios y las memorias - son parte integral de la obra de un escritor y que esa obra total es la revelación de la figura de su autor ("Ya sabemos que la verdadera persona de un escritor o de un artista está en su obra, sólo en su obra" [271]); y que las cartas gozan de buena salud aunque la privacidad intrínseca del género las mantenga fuera del alcance de los lectores.

En su lectura de este ensayo, Sylvia Molloy propone que toda la obra de Bianco - traducciones incluidas - es parafernaria, en un sentido "lateral" y lo explica así:

[P]odría decirse que su obra toda - y por esto entiendo tanto su obra de ficción, de traducción (esa famosa "otra vuelta de tuerca" a la que somete los textos ajenos), como su deslumbrante parloteo - es parafernaria. Obra poco numerosa, fragmentada, lateral, personalísima e indispensable, hecha de esas "small smothered intensely private things" - esas insignificancias silenciadas e intensamente privadas que son, para el Henry James de "The Beldonald Holbein", la materia esencial de la ficción. (23-24; énfasis y comillas en el original)

Molloy establece además que él reconoce un límite entre la realidad y la ficción que su escritura respeta: "[La escritura de Bianco e]s discreta y rehuye [sic] lo abiertamente confesional; a la vez, es profundamente autorreferencial, casi autobiográfica. Digo casi porque Bianco tenía plena conciencia del límite ... ante el cual había de detenerse, límite autoimpuesto que era, en cierto modo, su medida" (2I, énfasis en el original). Esta idea, de parte de una de las estudiosas de la autobiografía en Hispanoamérica, es quizá la menos definitiva y por ello la más tentadora como premisa de lectura. ¿Dónde se encuentra ese límite y qué significa aunque sea de un modo privado - trascenderlo, burlarlo, ignorarlo, con deliberación?

Bianco conjetura que la poca atención de sus contemporáneos hacia el género epistolar obedece a una falta de creencia en la posteridad. ${ }^{8} \mathrm{Si}$ revertimos su melancólica conjetura (el adjetivo es suyo), nos encontramos con una activa profesión de fe que se manifiesta en su 
decisión de transformar algunas cartas que Elena Garro le había escrito en materiales de su novela. Las incorporaciones son el objeto de este trabajo. Amén de la condición íntima y episódica de las cartas como registro biográfico, nos detendremos en una circunstancia concreta pero de extensión considerable: el dilatado proceso de composición y escritura de La pérdida del reino que estas cartas no sólo reflejan, sino que también integran, ya que varias de las escritas por Garro serán luego incorporadas como sustancia narrativa por Bianco en el texto mismo de su novela, como uno de los elementos constitutivos del personaje de Laura Estévez y de su voz. ${ }^{9}$

Publicada en I972, La pérdida del reino es el resultado de un arduo proceso de escritura, con cambios de ritmo y prolongadas interrupciones a lo largo de tres décadas. ${ }^{10}$ El aspecto que nos interesa aquí requiere que concibamos la novela pensando en la tensión entre vida y obra que Bianco entiende como algo irresoluble, en constante oscilación. Vale la pena recordar que La pérdida del reino es, entre otras cosas, una roman à clef ${ }^{\mathrm{I}} \mathrm{y}$, en tanto tal, dialoga con Testimonios sobre Mariana (i982), novela de Garro que contiene una ficcionalización parcial del mismo período. ${ }^{\mathrm{I2}}$ Cabe preguntarse hasta qué punto la lectura crítica se enriquece o se empobrece con la incorporación al análisis de elementos de la serie extraliteraria, en términos formalistas, desde una perspectiva biográfica o documental.

Si creemos, con Paul De Man, que "el momento autobiográfico ocurre como una alineación entre dos sujetos involucrados en el proceso de leer" (92I; mi traducción) - ya que no sería tanto una cuestión de referencialidad cuanto de efecto de lectura -, esto se daría dentro de un grupo cuya selectividad estaría amenazada por testimonios que revelan la cifra. Quien divulga esa clave lleva a cabo una operación que no sólo revela el secreto sino que exhibe, de modo patente, la figuración de la propia pertenencia. ${ }^{13}$ La clave funciona entonces como una criba: separa a los lectores capaces de descifrarla de aquéllos que la ignoran (y, en otra instancia, a quienes la conocen de primera mano de quienes saben de ella por los dichos de los primeros). Desde esta perspectiva, la novela en clave es propia de una camarilla (Boyde i56) y es un objeto que afirma su cohesión en virtud de la interpretación de la contraseña de la que sólo disponen los iniciados; por eso mismo, despierta curiosidad acerca del chisme literario que la alimenta (McCoy I28; I30-I33). Pero lo que caracteriza esencialmente a la novela en clave es que lidia de un modo conflictivo con el material factual y el ficticio (McCoy I28). Esa confluencia supone un problema precisamente allí donde borra los límites que demarcan el encuentro de la historia con la imaginación. 
La novela en clave consiste en un "modo literario que subraya la inestabilidad de las demarcaciones genéricas" (Judson 159) y es por eso que conviene a la perspectiva de Bianco. Juan García Ponce identificó tempranamente esta tensión en una reseña que no pretende desentrañarla sino advertir su irresolución: afirma que "la irrealidad está detrás de los personajes" (I2) y, al mismo tiempo, que la novela es "el retrato de un mundo que desaparece, retrato de una desaparición que alimenta al mundo: la realidad se viste de sombras" (I2). Para dar cuenta de la coexistencia de realidad e irrealidad, García Ponce se vale de metáforas como fantasmas y sombras para defender una lectura sin concesiones tranquilizadoras en el nivel de la referencia. ${ }^{14}$ Susana Zanetti, años más tarde, opta por la discreción al referirse a una "trama de desdoblamientos" (73) central en la novela y articularla con la "reflexión sobre la escritura de la ficción", sobre la que la narración hace especial énfasis.

Bianco se resiste así a la referencialidad como un código unívoco. A propósito de la relación de la novela con la realidad, María Moreno le preguntó abiertamente si está "basada en hechos reales" y la respuesta de Bianco fue taxativa: "No. La pérdida del reino es una obra de pura imaginación" (I6I). No faltan en la novela misma las reflexiones a propósito de esta cuestión; acaso una de las más inquietantes sea ésta: "No ignoraba que la vida real suele plagiar la literatura" (La pérdida 364$)^{15}$ Guillermo Sheridan, alineado con la insistencia en la novela como obra de pura imaginación, explica al respecto de Bianco que "esa verdad [la de la vida "real"] merecía su cuidado y justificaba sus afanes, sólo bajo la especie de lo literario" (76). Y definió, a propósito de La pérdida, como un "tipo de integridad ... la práctica de la realidad que consiste en imaginarla" $(76)$. Bianco, al desnaturalizar hechos y documentos de su historia personal, defiende la autonomía estética y, sobre todo, la preeminencia absoluta de la ficción sobre los géneros referenciales.

La pérdida del reino es entonces el metarrelato de la dificultad de Rufo para escribir una novela autobiográfica - nivel en el que la preocupación por el estatuto de la ficción adquiere consistencia literaria -, a la vez que el relato enmarcado de la vida del propio Rufo. ${ }^{16}$ Tiene cinco partes, la primera de las cuales está sin numerar y presenta el marco metanarrativo en la novela: en ella un narrador anónimo, empleado de la editorial Galaxia, describe su relación con Luisa Doncel, quien a su vez le presenta a Rufo. El narrador ayuda a Luisa a escribir la biografía de un pariente y luego recibe de Rufo los borradores de esa novela inconclusa. Esta parte termina con la muerte de Rufo, tras una misteriosa internación, y la posterior decisión del narrador de abocarse a la tarea de cumplir con el 
encargo: las cuatro partes que siguen son el resultado de ese trabajo (con algunas inserciones explícitas de la voz narrativa). ${ }^{17}$

La primera parte se inicia con las desventuras de Rufino Velázquez, Rufo, en un colegio religioso, donde conoce a su amigo Néstor Sagasta, y termina con el asesinato del padre. La segunda está dedicada al período siguiente, cuando él y su madre se instalan en el campo, en Tacuaras, donde retoman la relación con la familia Lara; posteriormente, Rufo viaja a Buenos Aires para estudiar derecho. Esta parte se cierra con la explicación judicial - y extrajudicial - del asesinato de su padre. En la tercera, Rufo y su madre viajan a Europa. A su regreso continúa con sus estudios - que no le gustan tanto como las letras - y traba amistad con un grupo de jóvenes gracias a quienes se reencuentra con su ex compañero del colegio, Néstor Sagasta. Conoce a Inés Hurtado, quien confiesa ser hija del padre de Rufo. Esta parte termina con el estallido de la Segunda Guerra Mundial y con la melancólica constatación de que Rufo ya es adulto y no ha "realizado ninguna de las esperanzas de su juventud" (284). La cuarta y última parte tal vez la de mayor intensidad narrativa - se concentra en la estadía parisiense de Rufo y se nutre de situaciones vividas por Bianco en el París de la posguerra. En esta parte final se encuentra el origen de la novela misma y es allí cuando, estimulado por Laura Estévez, Rufo empieza a escribir. Así, la novela culmina con la reconstrucción de su propio origen y, a un tiempo, con la muerte de su protagonista y autor.

El personaje que aquí nos ocupa es el de Laura Estévez, profusamente presente en la "Cuarta parte", esposa de Horacio y amante de Néstor Sagasta, amigo de Rufo, el protagonista. El punto de vista desde el cual se la contempla es, la mayor parte del tiempo, el de Rufo. En la enumeración de sus sucesivas apariciones, podrá verse el sinuoso camino que la lleva de ser una especie de intuición borrosa a ocupar un lugar privilegiado - si no el lugar - en los sentimientos del protagonista. Sutilmente, Laura se desliza dentro de la superficie narrativa y se apodera de ella con una intensidad inusitada.

La primera vez que se alude a su existencia es bajo la forma de una intuición o percepción que el protagonista descubre en su amigo, Néstor Sagasta: "Algunas noches después, también comiendo juntos, a solas, Rufo tuvo una especie de revelación. ¿Cómo no se le había ocurrido antes? Sintió en torno de Néstor una presencia desconocida, como el aura de una mujer" (3or; énfasis mío). La segunda se produce cuando, en diálogo con su amigo, se hace referencia a ella, pero todavía no se la nombra:

-No sé cómo explicar, pero te encuentro cambiado. Más amplio de ideas, más benévolo. Das la impresión de ser muy feliz. 
$-¿$ Te parece?

-Sí.

- ¿Estás enamorado?

-Sí.

- ¿Por qué no me lo has dicho?

-No sé.

$-¿$ Es francesa?

-No, es argentina. La conocí en México, antes de la guerra. Después volví a encontrarla aquí.

- ¿Y por qué no me has presentado?

- Me daría mucha pena que no te gustara.

-Estoy seguro de que habrá de gustarme.

-... o que te gustara demasiado, vaya uno a saber. Sería, entonces, la segunda mujer de la cual nos enamoramos los dos. (3OI-O2)

Enterado así de su existencia, la vez siguiente es ya el primer encuentro del protagonista con Laura:

Cassou se detuvo a saludar a una jovencita rubia, envuelta en pieles muy lujosas del mismo color y brillo de su pelo suelto. Hablaban en español. Después los presentó a Sandle y a Rufo.

-La señora Estévez es mexicana - le dijo a Rufo. Y a ella -: Velázquez es argentino.

-Yo también soy argentina - contestó la muchacha -, pero tengo las dos nacionalidades porque mi marido es mexicano. (302)

A continuación, Rufo ya tiene ocasión de expresar su primera impresión a propósito de Laura y lo hace de una manera tan negativa que empuja a la sospecha; el arco del enamoramiento se abre con la resistencia que lo impulsa a afirmar: "Yo la encontré muy impertinente" (302) y, más adelante en el mismo diálogo, "A mí me hizo muy mal efecto" (303). Esto no impide que la misma escena - y con ella, ese capítulo - se cierre con la siguiente referencia tras el recurso del narrador omnisciente: "Rufo pensaba en la mujer que Néstor había conocido en México, vuelto a encontrar en París, y de quien estaba muy enamorado" (303). A partir de este momento, se suceden en la novela los indicios del creciente interés de Rufo por Laura, incluido el límite de lo que el recurso le permite imaginar “Se habría fijado en él como él en ella?” (307) - sin que todavía se revele abiertamente el enamoramiento. Como si el narrador fuera presa de la misma ceguera casi pueril que parece imponerse el personaje, exclama: “iComo si hubiera peligro de que él se enamorara de esa muchacha!" (3II). Dos páginas más adelante, el narrador pierde por completo los reparos y 
se suceden frases tales como "pensaba a cada rato en ella" y "buscaba sus huellas en los muebles, en los cuadros, en la atmósfera del departamento" (313), así como los lamentos del amor no correspondido - "Laura seguía sin llamarlo" (314) - y las impresiones deliberadamente positivas acerca de ella: "comenzaba a parecerle encantadora. Era tan diferente de las francesas y de algunas hispanoamericanas que había conocido en París, $\tan$ ajena a cualquier convencionalismo" $(315) .{ }^{18}$ La curva del sentimiento culmina con un detalle de una intensidad provocadora. Se trata de la esperada comunicación telefónica en la que finalmente Rufo osa llamarla por su nombre: "Una mañana, cuando estaba medio dormido, sonó el teléfono. En seguida le reconoció la voz y se permitió decirle Laura. / Laura, Laura - balbuceó -, ¿ por qué ha demorado tanto en llamarme?" (315; énfasis mío).

Esta cuidadosa construcción paulatina y morosa del enamoramiento de Rufo ha de servirnos de telón de fondo narrativo para el examen de los fragmentos que propongo a continuación. Laura Estévez es para Rufo el objeto de deseo amoroso que ha ascendido desde la inmaterialidad de su aura sobre el amante hasta ocupar todos los sentidos del protagonista; ha recorrido la curva que nace en el rechazo, ese instante en el que el más tenaz de los miedos desaconseja el amor, hasta la desesperación signada por la rendición y la entrega absoluta. ${ }^{19}$

La presencia de las palabras que proceden de cartas de Garro dentro de la novela de Bianco, su destinatario, es abundante. Hay una infinidad de detalles que se esparcen aisladamente en las páginas de la novela y tres fragmentos de notable extensión, prácticamente incrustados sin alteraciones. ${ }^{20}$ En términos generales, Bianco no respeta la cronología de las cartas: cambia el orden, usa las cartas y episodios sin recomponer el orden original según la conveniencia del relato novelesco. No le interesa tanto el registro anecdótico, en cuanto documento histórico, como el tono que en ellas predomina, aquello que hace del personaje de Laura Estévez una recreación de las palabras de Garro.

Bianco conserva siempre la primera persona auténtica del texto epistolar y lo hace por medio de dos recursos: el diálogo y la carta. De los tres fragmentos largos que nos ocupan, los dos primeros consisten en diálogos donde la estructura general del material de las cartas está intervenido sólo en función de las necesidades del relato y Laura enuncia las palabras de Garro en largas intervenciones. El tercero es una carta de Laura a Rufo dentro de la novela; allí lo que se reproduce es una carta de Garro casi completa y las intervenciones autorales son de tenor muy distinto. A continuación pueden compararse, en columnas yuxtapuestas, 
los extractos de la novela publicada (a la izquierda) con las partes de las cartas correspondientes (a la derecha).

Primer fragmento de la novela

— ¿Le gusta el Guardi? —dijo ella—. Yo estuve en Venecia este verano. Decidimos con mi marido bacer una gira por Italia, y planeamos todo el viaje de una manera muy minuciosa. La primera ciudad que íbamos a visitar era Venecia. En efecto, llegamos a Venecia, que no conocíamos, y quedamos tan deslumbrados que nos pasamos cuatro semanas tomando café en la plaza San Marcos. Nada de lo que he visto me ha maravillado más que Venecia. Qué alegría sentíamos. Hacia no sé cuántos años que no éramos jóvenes, y Venecia nos bizo olvidar basta que estábamos casados.

— ¿Su marido es mayor que usted? -Apenas.

-Pero usted es muy joven.

-No se fie de las apariencias. Tengo un hijo que va a cumplir siete años. Bueno, le sigo mi cuento. En Venecia encontramos a un amigo italiano que nos llevó a recorrer la ciudad con toda una pandilla de escritores, pintores, críticos y periodistas que estaban allí con motivo de la Bienal. Le confieso que visité todos los museos y, lo que es peor, con entusiasmo. Mi marido decidio preferir el Carpaccio al Tintoreto, cosa que me indignó un poco: después de haber estado en Venecia comprendo el lujo, la sensualidad y el rojo. $\mathrm{Me}$ be cautivado de tal manera esa ciudad que hasta el Veronese, al cual antes despreciaba por superficial (fjjese si soy pedante), boy lo admiro. Un día, en medio de tanta agitación, se nos ocurrió hacer cuentas y resultó que no teníamos casi dinero. Entonces echamos a suertes a ver quién abandonaba el Paraíso, y me tocó a mí. A Horacio, mi marido, se le calmó un poco la conciencia porque ese mismo día, en un restarán, me dio una especie de vértigo y cai redonda. Yo creo que era de tanto andar. Quedó pues resuelto que él seguiria hasta Florencia y que yo, con la muerte en el alma, me iría a Suiza donde estaba el niño con la niñera, a esperar que nos mandasen dinero. (309-10)
De la carta “Agosto 15 de 1948 Saanen"

Estuve en Italia cuatro semanas con el Bello Tenebroso. Verás: este año Oc. tenía dos meses de vacaciones y decidimos gastarlos allí. Hicimos un plan minucioso y detallado de la gira, la primera ciudad que íbamos a visitar era Venecia. [...]

Estuvimos muy contentos, hacía no se cuántos años que no éramos jóvenes, y Venecia nos hizo olvidar hasta que estábamos casados. [...]

El Bello

Tenebroso decidió cambiar su preferencia de Tintoreto al Carpaccio; $[\ldots]$

hasta al

Veronese al cual antes despreciaba por superficial (Fijate que pedante soy) lo admiro ahora. [...]

ese mismo día en un restaurante me dió un vértigo y caí al suelo. Yo creo que era la fatiga de tanta barbaridad.

* Las imágenes sólo muestran detalles del cotejo, donde las partes comparadas se destacan en cursiva en las citas de la novela. Si bien las cartas son accesibles en su totalidad para los investigadores, no pueden incluirse aquí por la dificultad para obtener permiso para reproducirlas. Se omiten, en consecuencia, las palabras que Bianco transcribió casi textualmente, ya que pueden recuperarse a partir de las citas extensas. La distribución espacial de la columna derecha da cuenta de estas omisiones.

En este pasaje se retoman las ideas y algunas frases completas, pero se eliminan o ignoran trozos significativos, especialmente las referencias de Garro a "Oc." y la evocación de los comentarios de éste, que no llegan a la 
voz de Laura. Amén de la intrusión del instante dialógico (que se interrumpe con la frase operativa "Bueno, le sigo mi cuento" que, a la vez, funciona como pie para dar la debida continuidad a la cita), hay largos párrafos donde se recuperan frases enteras, la anécdota general y, sobre todo, el tono de la carta. La reproducción idéntica de interjecciones (como la parentética) y de la mayoría de las frases revela no sólo un atento trabajo sobre el detalle, sino que también permite intuir una especie de reverencia que yace tras el gesto de homenaje a la palabra ajena. Asimismo se advierte que en la edición que Bianco opera sobre las palabras de Garro a la hora de introducirlas en su novela atenúa algunas imágenes en un afán de corrección expresiva (como cuando cambia "Yo creo que era la fatiga de tanta barbaridad" por "Yo creo que era de tanto andar", por ejemplo); elimina repeticiones y superlativos, modifica la puntuación y sustituye otros detalles menores. En el ámbito del estilo, domeña los excesos y quita algunos matices al privilegiar otros.

Segundo fragmento de la novela

Para que veas [le dice Laura a Rufo], anoche estábamos invitados a una comida muy divertida. Pues no fuimos, ni Horacio, ni yo. Y como había solecito, y a mi suegro la embajada le ha puesto un automóvil, to acompañé a él y a una señora Fontainebleau. ¡Si vieras lo que era la señora! Una duquesa aburridisima. Me lo pasé muy melancólica no sé cuánto tiempo mirando el sombrero de Napoleón. ¡Pobrel Qué sombrerotes usaba. Su cama, su trono... Todo muy precioso. Claro que es cursi, pero como era de él yo estaba muy conmovida. [...] Hace días, como ha venido mi suegro, Horacio fue a una ceremonia militar en Saint-Cyr y volvió enloquecido con los uniformes rusos. Después de oir mi furia provocada por el libro de Kravchentoo, ese libro de baja calidad, los galones de los soviéticos lo bicieron casi comunista. "Son gente formidable, con esos ojillos tan ingenuos", etcétera, etcétera. Quería convidarlos, pero yo no lo dejé por Lorenzaccio. S sabe que recibimos a soviéticos, le da un soponcio. Horacio, para excusarse, debió decir que yo estab enferma porque la semana pasada llamó un general ruso a preguntar por mi salud, y como hablaba en español y creía que era chofer de la embajada y le decía todo el tiempo: "Gracias, Alberto; gracias, Alberto." Luego pidió a Horacio y éste por poco se desmaya al saber quién era y que yo le decía Alberto. Luego nos ban llegado una serie de tarjetas postales soviéticas muy convencionales. Pero como yo recibo el correo las be hecho perdedizas. Todo por Lorenzaccio. (323-24)
De la carta del "Lunes 12 de Enero de 1948"

Hace unos días me hice el propósito de buscar a alguien; y me revisé desde la primera hasta la última página la libreta con la lista de "amigos". Por fin me decidí por una señora y ayer me fui con ella a Fontainebleau. Me pasé muy melancólica no se cuanto tiempo mirando el sombrero de Napoleón. Pobre que sombrerotes usaba.

Octavio ha descubierto ahora sí; a unas gentes maravillosas. ¡Chicos realmente encantadores! Por supuesto que yo no me he dignado a ver estos nuevos descubrimientos.

Después de su furia provocada por el libro de Kravchenko (libro aburridísimo) los galones de los Soviéticos lo hicieron casi comunista.

Luego nos han llegado una serie de tarjetas soviéticas de Felicitación de Año Nuevo. Pero como yo recibo el correo las he hecho perdidizas.

* La referencia a Saint Cyr también viene de la carta, así como la anécdota del teléfono (ambas omitidas aquî). 
Aquí es notable cómo, en virtud de la construcción de una Laura despojada de todo rastro de patetismo, Bianco evita comentarios que Garro hace en sus cartas sobre la busca de "amigos" (la soledad o el aislamiento son un tema recurrente en sus cartas). Se omiten también, como en el segmento anterior, las referencias a la vida laboral y social de Paz. ${ }^{2 \mathrm{I}}$ Además de algunos retoques, se mantienen las anécdotas y especialmente las impresiones de Garro en las palabras de Laura en tanto reflejan una visión positiva del mundo, pero no las que trasponen el límite de lo privado; tanto el aburrimiento parisiense como el lamento por la soledad no alcanzan el ámbito público de la novela. Se insinúan así algunos de los rasgos del Bianco editor a la hora de una censura menos literaria que personal.

Este es, finalmente, el momento más revelador del cotejo: como la incorporación se hace en la forma de una carta dentro de la novela, la reproducción es casi textual (es la única carta que se reproduce completa), con cambios escasos y por eso significativos. Como se trata, especularmente, de una carta, está libre de constricciones estructurales y el tono de Garro penetra intacto en la novela como un atributo de Laura. ${ }^{22}$ Se trata de la incorporación más fiel, al margen de cambios menores, de puntuación, léxicos o que responden estrictamente a la necesidad de la trama (como el cambio de "niña" en la carta de Garro por "niño" en palabras de Laura). Las dos omisiones resultan flagrantes frente a la fidelidad casi devocional que guarda en todo lo demás; ambos cambios aparecen en las frases de carácter vocativo en las que Garro revela la cifra de su amistad. Le escribe a Bianco: "Y si no me crees ven" y "Todo lo que te digo es una invitación"; son frases cruciales en su contundencia y ausentes en la carta de Laura a Rufo. Estos borramientos alteran el tono que Garro había impreso en su carta a su amigo y este cambio se intensifica cuando Laura escribe, en la despedida: "Pero no quiero que tú vengas". El tono desesperado de Garro desaparece para dar paso a la personalidad independiente y, ya dentro de la trama, el rechazo de Laura Estévez hacia Rufo.

Dentro del marco de la punzante inquietud entre realidad y ficción sostenida en su imposibilidad de solución a lo largo del tiempo -, la confrontación de una parte significativa de esa "parafernaria", que tan vital era para Bianco, con algunos segmentos de su última novela es un ejercicio revelador. Resulta sorprendente descubrir cómo ciertas cartas de la "vida real", escritas por Garro, se transformaron en algún momento del dilatado proceso de escritura en material fértil para la ficción. ${ }^{23}$ En este ejercicio de apropiación de la prosa epistolar de Garro como materia para su propia novela, Bianco lleva a cabo una doble operación, intrínsecamente determinada por su dualidad y por la reciprocidad de sus partes. Además 
del cuidadoso trabajo de selección, exhibe un respeto casi reverencial por la palabra de Garro, por su entonación y cadencia, toda vez que Garro da con el tono que Bianco busca para Laura Estévez. ${ }^{24}$ Sin embargo, esta insistencia en la forma con que la escritora mexicana concibe el mundo, hace más evidentes las alteraciones practicadas por Bianco y acusa más las que omite. Así, las que cambia cobran una importancia inusitada a la luz de su tan aplicada fidelidad; las que descarta, en cambio, delatan su intención.

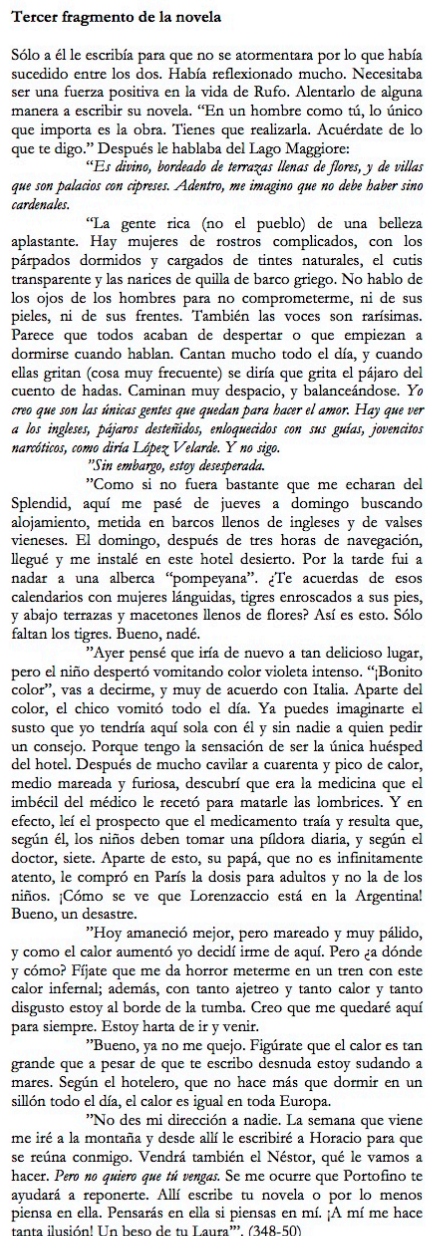

* La descripción de la gente es idéntica en la carta, así como el relato de la busca de alojamiento, la enfermedad de la niña (en la carta) y las referencias al calor. 
En distintos momentos de la novela, Bianco cita partes de casi todas las dos docenas de cartas anteriores a la publicación de La pérdida del reino que se conservan. Los segmentos más largos proceden de la primera, la segunda y la cuarta cartas, pero de la tercera no cita sino un puñado de palabras. Con las restantes ocurre lo mismo: sólo cita episodios sueltos y anécdotas que, en las cartas, no ocupan más de un par de líneas. ¿Cómo elige? ¿Qué omite? ¿Por qué transcribe casi enteramente tres y las demás no? En la tercera carta, Garro escribe acerca de la muerte del cuñado de Bianco, tema sobre el que se extiende bastante en términos más generales. También escribe sobre la soledad, sobre Octavio y lo que llama las "nuevas amistades" de éste. De esta carta sólo se refiere un comentario acerca de los billetes de cinco mil francos (336). En el resto de las cartas, las partes excluidas del material novelesco son la mayoría: lo descartado puede organizarse en tres grandes temas. En primer lugar, Bianco suprime lo que Garro escribe sobre otras personas (Octavio Paz presenta el ejemplo más evidente a primera vista ${ }^{25}$ y en las cuales puede apreciarse su extraordinaria maledicencia. $^{26}$ En segundo lugar, los extensos segmentos de tono plañidero, muy abundantes en esta correspondencia, tampoco trascienden los límites de lo privado: allí es donde Garro abunda en lamentos por la soledad o glosa la tristeza. Por último, Bianco omite sistemáticamente la creciente paranoia que se apodera de las palabras de su amiga: tanto en el plano personal como en el literario y el político, Garro describe en sus cartas todo tipo de persecuciones que la tienen por objeto. ${ }^{27}$ Todos los comentarios de índole más o menos política de las cartas quedan fuera de la novela. ${ }^{28}$

La operación de edición textual que Bianco practica sobre Garro, a través del material tomado de sus cartas, es el procedimiento esencial para la creación del personaje de Laura Estévez: estas supresiones son esenciales, voluntarias y marcan una deliberada orientación en la construcción del personaje. Las maniobras de edición que practica Bianco en este traslado, paralelamente a la apropiación de las palabras de Garro, son para despojarlas de su temperatura emocional, mediante la supresión premeditada de algunos personajes, episodios o comentarios. La reproducción queda así enturbiada por una clara intención de producir una imagen favorable de la mujer que se evoca, libre de los patetismos y constricciones de la original. Las referencias más circunstanciales, aquéllas que denuncian la diferencia entre vida vivida y vida novelada, son las que más rápidamente desaparecen o se deforman. Las más notables son las que muestran a una mujer vulnerable y con zonas oscuras o reprobables en su conducta. De este modo, Laura Estévez conserva lo "mejor" que Garro ofrecía en sus cartas: el lirismo y la diversión de su tono, la 
insistencia y el entusiasmo que transmite su escritura. Finalmente, el personaje de la novela termina por transformarse en una suerte de dínamo de energía y de confianza que impulsa a Rufo a dedicarse a su novela casi compulsivamente. ${ }^{29}$

En los segmentos vocativos de sus cartas y en su procesamiento dentro de la trama de la ficción, la novela ofrece una versión especular, en negativo, de las palabras y la intención de las cartas, conservando lo expreso de la manifestación: Laura escribe a Rufo exactamente lo contrario de lo que Garro había escrito a Bianco. Donde decía "ven” y "todo lo que te digo es una invitación", dice "no quiero que vengas". Esto forma parte también - llamativamente - del trabajo de edición señalado en el párrafo anterior, que implica un movimiento reflexivo de Bianco sobre Rufo, que se vale del procedimiento de la composición textual para revisar con una deliberada cuota de invención la mirada que se le dedica. ${ }^{30}$ Estas dos operaciones sugieren que es posible pensar una analogía entre esta construcción del personaje de Laura Estévez y la labor de edición de Bianco; las cartas de Garro, así como su persona, ofrecen al autor un material sobre el cual operar y editar para poder incluirlo en La pérdida del reino, del cual resulta una mujer emocionalmente mucho más independiente y simple que su amiga y, para usar una imagen censurada por él mismo, un dechado de supuestas o engañosas perfecciones.

Una cuestión muy repetida tanto en la correspondencia como en la novela es la importancia de las obras literarias y de la necesidad de abocarse a ellas. Ambos escritores se urgían mutuamente a la consecución del trabajo literario. Este aspecto se traduce en un rasgo crucial del personaje de Laura Estévez. Es Laura quien insta a Rufo a escribir y quien en la novela se coloca como una de las principales motivaciones para la escritura, así como su única destinataria. Rufo dice a Laura que - casi al igual que Bianco - escribe "sólo artículos", a lo que ella responde: "Es lástima. ... Deberíamos escribir una novela juntos, una novela diferente de la vida y que por eso mismo se pareciera a la vida en sus momentos más altos. Con imaginación, con fantasía, con poesía” (3I $7^{-1} 8$ ). Poco después, se explica que "Laura lo instaba a escribir una novela" (328). De inmediato, Laura misma se convierte en un tema posible: "A Rufo no le interesaba el Príncipe Mixteco [sobre quien Laura lo insta a escribir]. Hubiera preferido escribir una novela sobre Laura" (329). ${ }^{3 \mathrm{I}}$ Sin embargo, la idea de ella como tema se desvanece al tomar contacto con el pudor de Laura, quien le responde: "Para que escribieras una novela sobre mí tendría que contarte cosas de mi vida. Y es mejor olvidarlas" (329).

Las sucesivas reflexiones sobre la novela - que, como sabemos, no es otra que la que estamos leyendo - están constantemente iluminadas por 
los encuentros con Laura, ya sea como motivo, como tema o como lectora anhelada:

Sentía orgullo de que Laura confiara en su talento. ¿Llegaría a escribir esa novela que le pedía como un homenaje a ella? La novela era un género que no había abordado jamás. ¿Y qué otra cosa podía poner en una novela sino su propia vida, una vida $\tan$ chata, tan carente de interés? (350)

[Su novela n]o sería una novela poética. Volvía a decirse que sólo podía escribir sobre sí mismo, sobre su vida, y cuando pensaba en su vida no encontraba apenas otra cosa que pequeñeces, decepciones, traiciones, melancolía, sexo ... Lo redimía su afán de verdad. Quería no favorecer su carácter, ni siquiera con un defecto. Corría el peligro de aburrir a Laura, que soportaba todo menos el tedio. (353)

Todo lo que había en él de sincero lo reservaba para su novela. Y en su novela, desprovista de ornamentos, de un estilo muy sencillo, le preocupaba respetar los hechos, por inverosímiles que parecieran, e interpretarlos con la mayor buena fe. Estaba escrita bajo la advocación de Laura, y sabía por adelantado que a Laura no habría de gustarle. $(358)$

Laura está en el origen de la idea de escribir una novela - que es, a su vez, en una puesta en abismo, la novela en la que leemos la escena en la que se describe su propio nacimiento -, así como lo está en su núcleo, como tema posible (o, como de hecho lo es, como personaje) y también se ubica privilegiadamente en el extremo final, siendo como es su destinataria o lectora ideal.

Esta insistencia en la importancia de la obra, en la necesidad de dedicarse a ella como justificación y fruto de una vida está presente en las cartas que Garro le escribe; la preocupación por la escritura y la entrega a la propia obra era una preocupación compartida entre ambos. A modo de ejemplo elocuente, valga el que sigue. En una de sus cartas, Garro increpa a Bianco, mencionando las que considera - en su opinión - son sus respectivas distracciones principales (y reprensibles) que les impiden escribir. Después de invitarlo a París y de enumerar las cosas que podrían hacer juntos, le escribe:

Y tú escribirás muchas horas encerrado en tu cuarto. No es posible que tires tu talento en las obritas de los demás. // Sería tristísimo que Dios nos recogiera en este momento y nos llamara a cuentas. "¿Y qué hizo usted con los dones que le dí?" Yo pelear con Octavio Paz y huir de Archi Burns. Y yo Pepe, discutir con la Reina Victoria. [I-2, "Junio I9 de I96I"]..$^{32}$ 
Podemos decir con Beatriz Colombi que "[l]a carta establece una enunciación desdoblada e impostada, presume confidencialidad mientras aspira a la publicidad, lo que hace que el intercambio sea falsamente secreto y discretamente público" (45I). Es en este terreno resbaladizo, en que el juego entre ficción y realidad potencia su capacidad de ambigüedad y su indefinición unívoca, donde Bianco toma las cartas de Garro como material narrativo, en una puesta en abismo que borra sus propios rastros para atentar contra esa tersura del estilo tan invocada por la crítica. ${ }^{33}$ Esta operación, lejos de anular o atenuar la tensión que describíamos al principio, no hace en este caso sino acentuarla, tomando como eje el vértice Garro-Laura Estévez. ${ }^{34}$

Laura Estévez es el fruto tanto de las vibrantes palabras que Garro le escribió a su amigo Bianco, como de la fascinación de ese destinatario atento y meticuloso, concentrado en una obsesiva estilización del material autobiográfico. En el personaje de Laura Estévez confluyen no sólo el carácter lírico de su voz, sino también esa especie de fuerza motora que impulsa la escritura, despojada de todo aquello que - a los ojos de la labor editorial de Bianco - opacaba a la persona real. No se trata estrictamente de una idealización pura: Bianco no traduce sus ideas propias para construir un personaje abstracto y perfecto. Es antes bien un trabajo de destilación que Bianco opera sobre la imagen de Garro para dar con una Laura Estévez funcional al personaje que necesita en La pérdida del reino: aquélla que lo impulsará a escribir esa novela que no deja de resistírsele. Ya es suficiente con el tono sombrío de las secciones previas de la novela y con el que emana del propio Rufo: Laura ha de ser luminosa y sonriente, liviana y entusiasta, candorosa y poética, tanto como Garro demostró ser en sus primeras cartas a Bianco. Leer los fragmentos de las cartas incorporados constituye sin duda una revelación que permite descubrir una dimensión adicional en la referencia explícita a Garro en la "Crónica mexicana" que Bianco publicó en i967:

Pero nada es tan idéntico a la personalidad de Elena Garro como sus libros. Al leerlos, reconocemos sus ademanes, sus gestos, su sonrisa, el destello candoroso o dramático de su mirada. Asistimos al milagro de su conversación: la misma inteligencia, la misma coherencia, y esas imágenes que nos revelan la identidad imprevisible de los seres y las cosas. Adoptamos su visión del mundo. Una visión inusitada, poética, profundamente real. (327)

Hay en la incorporación de los fragmentos epistolares como material narrativo en La pérdida del reino una profesión de fe y acaso de amor, un 
tributo secreto e intencionadamente imperceptible. Las cartas de Garro procuraron las "insignificancias silenciadas e intensamente privadas" que nutrieron el personaje del que depende la posibilidad de narrar.

\section{CUNY, John Jay College}

\section{NOTAS}

I Este trabajo debe su impulso inicial a mis conversaciones con Daniel Balderston y con Juan Sobrino. Agradezco a Mariela Blanco, Betina González, Julieta Yelin e Irina Garbatzky; con sus inteligentes sugerencias, han enriquecido con generosidad y paciencia este trabajo. Agradezco, asimismo, a Judith Podlubne y Sandra Contreras sus agudos comentarios sobre una versión seminal que presenté en las "II Jornadas internas de Investigación 'Cuestiones críticas'”, Rosario, 20I2, y a Ernesto Montequin, su rigor y su ayuda.

2 Se conservan veintiséis en la Princeton University Library. Allí hay también cinco cartas tardías de Bianco en el archivo de Garro. Para una descripción de esta correspondencia, ver Melgar.

3 Algunas notas de Garro al respecto se encuentran entre los desordenados apuntes de Testimonios sobre Elena Garro. Las referencias a Bianco comienzan con “...José Bianco... llegó a París...” (I59) en 1946, terminan con “Se fue Pepe” (I70) al año siguiente, e incluyen numerosos comentarios predominantemente despectivos sobre su amigo, en consonancia con el tono de desprecio que la voz filtrada de Garro dedica a muchos de los hombres en este segmento de los "testimonios". Según la "Cronología" que Bianco incluye en Ficción y reflexión, su viaje a Europa data de 1946 y la "vuelta" dos años más tarde (4I7-18). En una carta de Victoria Ocampo a su hermana Angélica, se refiere el interés de Bianco por viajar a Europa de la siguiente manera: "Recibo hoy una carta apremiante de Pepe pidiéndome que le pida una beca para él a d'Ormesson. Si no la consigue me asegura que será muy desgraciado. Yo no necesitaba saberlo para tratar de que obtuviera su beca. De Sur no me dice nada concreto sino que ya se arreglará todo (!). Lo urgente es obtener la beca ... ¿Estabas enterada de esta decisión o de este deseo? A mí me toma muy de sorpresa. Me parece perfecto que Pepe viaje y se entere de lo que pasa en el mundo, directamente. Pero me parece que podría haberme dicho de la persona o personas que piensa dejar en Sur. Y si se trata de una ausencia momentánea o definitiva. Nada de eso sé. Nada de esto menciona en su carta. Mañana le telegrafiaré a d'Ormesson y también le escribiré sobre el particular. Me imagino que no será tan difícil obtener la beca. Me imagino que Pepe viendra 
rejoindre Mika Etchebehere. Le atribuye grandes méritos, él, tan severo para otras personas que valen más que ella" (380-8I).

4 Los encuentros entre Garro y Bioy Casares se limitan a una serie de tres momentos: París, 1949; París, 1951; Nueva York, 1956. El intercambio epistolar se extiende al menos durante veinte años.

5 Entre los más tempranos se encuentran "Casanova” y "Postrer etapa de Fénelon". Además de los que se analizan aquí, abundan en este tema "Proust y su madre", "Centenario de Proust", "Diarios de escritores” y "El ángel de las tinieblas", entre otros.

6 Sobre esta cuestión, ver la ilación de ideas de Chitarroni (65-67) al respecto, en la que se detiene en cuestiones como imaginación, verdad, realidad, mentira y ficción. En el mismo sentido apunta la confrontación que propone Balderston (9-10) y que retoma como tema un poco más adelante (I4-15). Prieto Taboada, en cambio, pretende "resolver" esta cuestión como una especie de recurso estilístico o de buscado efecto de lectura (39).

$7 \quad$ Nótese que "Digresión" formaba parte, según lo indica una nota al pie, de una novela en preparación. Si bien el texto no aparece en esta forma en La pérdida del reino, sí lo hacen algunos de los temas; aunque no se lo incluya textualmente, la preocupación común impregna la obra. Para un análisis del vínculo problemático entre literatura y lo real en las primeras reseñas y cuentos de Bianco, ver Podlubne 207.

8 "Hay pocos diarios y memorias de escritores. Ni siquiera se estila la publicación de cartas. Casi podría decirse que nadie cree en la posteridad, nadie cree en la supervivencia del espíritu, nadie cree en otra cosa que no sea el breve paso de la vida humana" ("Parafernaria" 272).

9 Abordar este cotejo desde un punto de vista intertextual, con su abundante espesor referencial, presentaría una dificultad metodológica central porque debería fundarse, forzosamente en el binomio público/privado. De acuerdo con Gerard Genette en Palimpsestos, habría un caso de intertexualidad en tanto "relación de copresencia entre dos o más textos, es decir ... como la presencia de un texto en otro" (Io); pero este juicio depende de "una decisión interpretativa del lector" (I9), lo cual en este caso sería improbable. Desde el punto de vista de la crítica genética, las cartas de Garro constituyen un avanttexte o pre-texto que forma parte de la génesis de la escritura de la novela de Bianco. Al ceñirme a la lectura de la novela y tratar su relación con las cartas como eminentemente nutricia, las entiendo como una "huella visible de un proceso creativo" (Lois 2).

IO En “Conversación con J. B.", entrevista incluida en Ficción, Bianco describe el proceso a Danubio Torres Fierro en estos términos: "Empecé a escribirla a fines de I950, a ratos perdidos, y cometí el error de publicar aquí y allá, antes de haberla terminado, algunos fragmentos de los que luego prescindí parcial o 
totalmente. Estaban de más. ... En 1955 la abandoné por completo. Hasta me molestaba que me preguntaran por ella. Quince años después, porque andaba bastante aburrido, decidí continuarla. Busqué mis viejos originales, eché al canasto buena parte y entonces la escribí, puede decirse, de un tirón. En un año y medio. Mientras la escribía, puedes figurarte, se me pasó el aburrimiento. Trabajaba todas las tardes, de dos a ocho" (406). Esto fue tempranamente anotado en las reseñas. Acerca de la recepción de este hecho entre algunos amigos de Bianco, como Victoria Ocampo y Octavio Paz, ver Melgar 426-27.

I2 Si bien el cotejo entre ambas novelas escapa al propósito de este artículo, este dato es crucial para dilucidar el modelo del personaje que nos interesa, Laura Estévez, ligado con el mismo referente que Mariana. Al respecto de la novela de Garro, ver Amador y Winkler. Desarrollé un análisis de las estrategias mediante las que se construye este personaje, muy distinto del que aquí nos ocupa, en "Procedimientos erosivos", en particular, pp. 520-24.

I3 A propósito de los nombres propios con los que pueden tenderse relaciones de identidad, Paz Leston señala, sin resolver identificaciones directas: "Otra serie de anécdotas [que Bianco contaba a sus amigos] se referían a su larga estadía en París en 1947 y I948: allí aparecían Octavio Paz y Elena Garro, Finki Aristarain, Adrienne Monnier, Mme Tezenas, Loli Larivière, Christian Bérad, Gide y Mauriac; llevan otros nombres en La pérdida del reino" (238).

I4 No todas las lecturas posteriores exhiben esta lucidez. En el breve comentario que el catedrático albaceteño Vicente Cervera Salinas le reserva a la novela, repara en "los rasgos de la confesión y el espíritu de atento observador del mundo" (II9) del narrador.

I5 El problema de la invención y la realidad, reñidos en tanto nociones mutuamente excluyentes está presente en toda la obra de Bianco. En La pérdida, leemos: "Se dijo [Rufo] que las personas no se reconocían a sí mismas, que tampoco reconocían a sus amigos, y que una novela, por autobiográfica que sea, es siempre una novela, es decir una historia inventada. Acaso él mismo se hubiera inventado" (358). Por otra parte, las transcripciones de las cartas respetan su grafía.

I6 Para un análisis estructural de estos niveles, ver Aponte y, más recientemente, Arrigoni de Allamand. Esta última señala la "ruptura del pacto ficcional" (2II) que resulta de estos juegos, y propone leer la novela al mismo tiempo como "una teoría de la novela" (2I2) y "una vía de acceso a la teoría que en ella se construye".

I7 Tal vez estas inserciones correspondan en la ficción a lo que Judith Podlubne identifica como el "novelista crítico" (I87) y sus intrusiones constantes sean una encarnación de su afán de ubicuidad (I95). 
I8 De gran interés es reparar en esta "diferencia", resultado del ejercicio de comparación, como idea que se repite en una efusiva carta de Bianco a Garro, donde aquel le escribe: "Aquí tienes ... un amigo que has deslumbrado y que cuando te compara con las demás mujeres (todas, sin excepción) las encuentra aburridas, banales, vanidosas, ininteligentes, bachilleras (algunas), sensuales (no, sensoriales), mezquinas" (carta fechada el 23 de noviembre ¿1951?).

I9 El cuento de Bianco "El límite", con el triángulo formado entre Jaime, Carlos Horacio y Bebé, ofrece una primera versión de este motivo del hombre que se enamora de una mujer a través de la imagen que su amado proyecta de ella. Hugo Beccacece, citado por el propio Bianco, anota tempranamente que "en realidad [Jaime] se ha enamorado de las palabras de su compañero [Carlos Horacio] más que de una mujer [Bebé]" (I2). Del mismo modo que ocurre aquí, el go-between es una figura cara a Bianco, quien a su vez tal vez haya cumplido con ese rol a su regreso de Europa. Para interpretaciones de los triángulos amorosos, ver Sedgwick (quien rastrea, a su vez, las lecturas de estos desde René Girard en adelante).

20 Entre los muchos fragmentos de las cartas que aparecen en la novela están las referencias al médico japonés, la huída en metro, el personaje del padre de Horacio, el soplo en el corazón, el mucamo Narciso, las fantasías de casarse con un campesino y vivir cerca de Roma, la enfermedad que ella llama "derrumbe", un tal "Nico", dueño de Rose Rouge, la película que Genet la invita a ver, la descripción de Genet, la decepción de Suiza. Melgar comenta algunos de estos detalles (428-29).

2I Todo lo que tiene que ver con Paz es material sensible a la hora de la reescritura. En otro momento, Bianco no resiste la tentación literaria de tomar una imagen de Garro en la que se proyecta divorciada del marido, pero es incapaz de concebir esta idea, a la vez que se ve tentado por sus consecuencias. Por eso la anécdota debe, necesariamente, cambiar de forma. En la carta "Mayo io de I949", se lee "Hubo un momento en que pensé divorciarme de Oc y casarme con uno que tiene una casa en el campo, cerca de Roma, y que se dedica a la caza. Es una especie de campesino muy encantador. Y a mí la idea de cambiar completamente de vida me pareció emocionante. Me gustaba la casa, la familia, los perros muy inteligentes, con manchas doradas en las orejas, los rifles. Estuve allí varios fines de semana, el chico es muy guapo y muy elocuente, pero la idea de tener niños y de dormir con él me contrariaba mucho. Entonces me vine a París. Prometí volver y tramitar el divorcio. No he tramitado nada". En la novela: "Y pensar, decía Laura, que en lugar de estar casada con Horacio hubiera podido ser la mujer de cualquiera de estos muchachos medio campesinos y vivir en una finca cerca de Roma, llena de niños" (356). Al eliminar por completo la fantasía del divorcio, el personaje está en cierto modo controlado, no ya en un nivel estilístico, sino más bien moral. 
22 En la novela, las cartas de Laura se mientan de la siguiente manera,

incorporando un guiño que se recuperará más adelante: “Cuando Néstor tuvo que volver a Buenos Aires, sostuvo con Laura una correspondencia asidua. Laura escribía como hablaba, con la misma elocuencia, humorismo, rapidez, volubilidad, facilidad. En sus cartas, Néstor empezó a descubrir sus sentimientos" (32I).

23 Las cartas no son el único material preescrito que Bianco usa en este proceso, en especial para la cuarta parte, que incluye reescrituras de textos que había publicado con anterioridad.

24 Según Lucía Melgar, el estilo “llamó la atención” de Bianco (429).

25 Así se pierde este breve fragmento satírico: "Ha Oc. le entró una especie de locura, se olvidó de sus habituales preocupaciones; hombre primitivo, mitos, embajador, etc. y se convirtió en un chico encantador". Sin embargo, no puede evitar la tentación de incluir el apodo que ella deparaba a su marido en las cartas, el "Bello Tenebroso", aunque atribuido a otro personaje (La pérdida 3IO).

26 Fuentes es "el burócrata culto mexicano" ("Lunes I9 de Febrero de 1962 París"); de Paz dice que es, "un pozo hipócrita de rencor" ("París 22 de octubre de I96I"); de Elvira Orphée, "a mí los bichitos me asustan" ("Octubre 6 de 1962 París"); de Esmeralda [Almonacid], "Qué nombre tan verde para la luz tan negra que despide" ("Junio 2 de 196r Ascona"). Es iluminador conocer el contenido de las cartas para leer de otro modo la respuesta de Sagasta cuando Rufo le dice que Laura es buena: “¿Buena? Es una sierpe.” (326).

27 Éstas serán objeto de la obra literaria tardía de Garro. Para una división de la escritura de Garro en 1968, ver Mora; para un análisis de los procedimientos en tres obras tardías, ver Rossi.

28 Tanto la maledicencia ingeniosa como un cándido interés en la política se ven en Memorias de España 1937. La ideología política que Garro elabora allí, tal como la de las cartas, es bastante ingenua y se confunde constantemente con las ideas persecutorias en el plano personal. Sobre esta obra, ver Mudrovcic.

29 Deleuze y Guattari, a propósito de Kafka, hablan del "móvil epistolar", del vampirismo de las cartas y afirman que "las cartas deben aportarle sangre y la sangre debe darle la fuerza de crear. No busca [Kafka] en lo absoluto una inspiración femenina, ni una protección maternal; sino una fuerza física para escribir" (47).

30 A veces las citas pertenecen en cartas que escribe a Néstor (como en p. 32I).

3I Cabe pensar, a la luz de esta cita, el recorte de las referencias a Paz que vimos en el cotejo. Algún documentalista no dejaría incluso de subrayar la importancia de la amistad que Bianco mantuvo con él. 
32 Una conocida versión de este imaginario encuentro con Dios, donde el elemento de peso para el "juicio" es el placer de la lectura, no el de la escritura, cierra el ensayo de Virginia Woolf "How Should One Read a Book".

33 La calificación de "invisible" para el estilo de Bianco que Borges impuso desde su temprana lectura de Las ratas determinó muchos de los comentarios posteriores. Balderston hace referencia, a propósito de La pérdida del reino, a la "sencillez sólo aparente, que revela niveles de gran complejidad estructural en sucesivas relecturas" (8).

34 No hay en las cartas de Garro signos de reconocimiento de sus propias palabras (las cartas están fechadas casi treinta años antes). Lee la novela y escribe: "Releí la novela. ¡Qué tristeza! Dime ¿así era la vida o así la veías tú? Mi pregunta es idiota. Las novelas nunca son la vida, son novelas. La leí otra vez de una tirada y me detuve en muchos párrafos y medité sobre muchas frases. “QQué bien escriben los hombres!” ... Entonces lo entendí más o menos, pues sigo con la sensación de que tu novela es nuestra novela. No sólo tuya y mía, sino de todos: Victoria, Octavio, Silvina, Bioy, Pepe, Ricardo, y que de alguna manera nos has echado a andar en un mundo conocido y desfigurado por su falta de limitaciones ... Esa Laura dice muchas tonterías." (Noviembre 2I de I972, New York). La lectura parece transportarla - pacto ficcional mediante -, transfigurarla en aquella cuyas palabras no son otras que las suyas propias y parece precisar conjurar ese desplazamiento de manera explícita, al decir "Ya fuera de Laura" para poder continuar con su relato neoyorquino. Esta carta comienza con la lectura de La pérdida y termina con la escritura de Testimonios sobre Mariana.

OBRAS CITADAS

AMAD OR, DIANA. "Elena Garro y las perspectivas de la memoria. Relato fotográfico de una vida equívoca”. Elena Garro. Recuerdo y porvenir de una escritura. Eds. Luzelena Gutiérrez de Velasco y Gloria Prado. Toluca: Tecnológico de Monterrey/Universidad Iberoamericana/Fondo Nacional para la Cultura y las Artes, 2006. 43-57.

A P ONTE, BÁRB ARA B. "La voz narrativa en La pérdida del reino". Explicación de Textos Literarios 6.I (1977): 37-44.

ARRIGONI DE ALlAMAND, Luz MARía. "De novelas y metanovelas: La pérdida del reino de José Bianco". Revista de Literaturas Modernas 27 (I994): 209-I6.

B ALDERSTON, DANIEL. "Introducción. Las lecciones del maestro". Balderston 7-I9.

-. с о м P. Las lecciones del maestro. Homenaje a José Bianco. Rosario: Beatriz

Viterbo, 2006.

B IAN Co, José. Ficción y reflexión. México DF: Fondo de Cultura Económica, 2007.

-. La pérdida del reino. México DF: Fondo de Cultura Económica, I990. 
-. "Prólogo". Las ratas. Sombras suele vestir. Caracas: Monte Ávila Editores, I985. 720.

B OYDE, MELISSA. "The Modernist Roman à Clef and Cultural Secrets, or I Know

That You Know That I Know That You Know". Australian Literary Studies 24.3-4 (2009): $155^{-66 .}$

CERVERA SAlinas, ViCEnTE. "El reino de José Bianco". Filología y Lingüística 27.I (2OOI): II3-22.

C Hit A RR ONI, LUis. "José Bianco: El mundo a tientas (There are less things)".

Balderston 65-69.

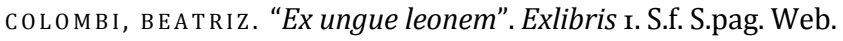

Deleuze, gilles y FÉlix GuAttari. "Los componentes de la expresión”. Kafka.

Por un una literatura menor. México DF: Era, 2008. 45-65.

DE MAN, PAUL. "Autobiography as De-facement". MLN 94.5 (1979): 919³0.

garcía PONCE, JUAN. "La pérdida del reino". Plural I7 (1973): I2.

Gar ro, elena. "Carta s". José Bianco Papers. Department of Rare Books and

Special Collections, Princeton University Library. S. pag.

-. Testimonios sobre Mariana. México DF: Grijalbo, I98I.

GENETTE, GE RARD. Palimpsestos. La literatura en segundo grado. Madrid: Taurus, I989.

JUDSON, BARBARA. "Roman à Clef and the Dynamics of Betrayal: The Case of

Glenarvon". Genre 33 (2000): $15 \mathrm{I}^{-} 70$.

L O IS, É LIDA. Génesis de escritura y estudios culturales. Introducción a la crítica genética. Buenos Aires: Edicial, 200I.

M C C O Y, LA U RE N. “Literary Gossip: Caroline Lamb's Glenarvon and the Roman à

Clef". Eighteen-Century Fiction 27.I (2014): $127-50$.

melgar, LuCía. "Correspondencias literarias. Bianco, Garro y La pérdida del reino". Actas del XIV Congreso de la Asociación Internacional de Hispanistas. Vol. 4. Coords. Isaías Lerner, Roberto Nival y Alejandro Alonso. Newark: Asociación Internacional de Hispanistas, 2004. 425-30.

m o loy, sylvia. Acto de presencia. La escritura autobiográfica en Hispanoamérica. México DF: Fondo de Cultura Económica, 1996.

-. "Figuración de Bianco". Balderston 2I- 28.

M ORA, GABR IE LA. "La familia: política, exilio y escritura en la obra de Garro". Letras Femeninas 29.2 (2003): 36-68.

MORENO, MARía. "La edad de la discreción". Balderston 155 -63.

MUdROVCIC, MARía EugEnia. "Memorias de España 1937. Un cuarto propio cercado de lo abyecto". Letras Femeninas 29.I (2003): 175-86.

o CAM P o, vict OR IA. Cartas de posguerra. Nueva York - Londres - París, marzo-

diciembre 1946. Buenos Aires: Editorial Sur, 2009.

PAZ LESTON, EDUARD O. “Mi amistad con José Bianco". Balderston 233-46. 
P ODLUBNE, J UDITH. "José Bianco: el escritor well timed". Escritores de Sur. Los inicios literarios de José Bianco y Silvina Ocampo. Rosario: Beatriz Viterbo/UNR, 2OII. $173^{-255}$.

PRIETO TABOADA, ANTONIO. "Amistades literarias y proyecto de autonomía". Balderston $29^{-} 45$.

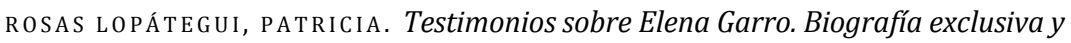
autorizada de Elena Garro. Monterrey: Ediciones Castillo, 2002.

ROSSI, MARÍA JULia. "Una poética de la incertidumbre: procedimientos erosivos en tres obras de Elena Garro". Nueva Revista de Filología Hispánica 62.2 (2014): $5^{1} 5^{-536 .}$

SEDGWICK, EVE Kos ofS Ky. Between Men. English Literature and Male Homosocial Desire. Nueva York: Columbia UP, 1985.

SHERIDAN, GUILLERMO. "El honor a la verdad". Vuelta i62 (I990): 76-77.

torRes fierro, danubio. “Conversación con J. B.”. Bianco (2007): 399-407.

WIN K LER, JULIE A. Light into Shadow: Marginality and Alienation in the Work of Elena Garro. Nueva York: Peter Lang, 200I.

wo olf, virginia. "How Should One Read a Book?". The Second Common Reader. Nueva York: Harcourt, Brace y Company, 1932. 28I-95.

Zanet Ti, S USANA. "La transparencia de José Bianco". Quimera 66-67 (I988): 70-73. 